\title{
Usefulness of a large field of view sensor for physicochemical, textural, and yield predictions under industrial goat cheese (Murcia al Vino) manufacturing conditions
}

\author{
S. Rovira, ${ }^{\star 1}$ V. García, ${ }^{*}$ E. Ferrandini, ${ }^{*}$ J. Carrión, $†$ M. Castillo,‡ and M. B. López \\ *Department of Food Science and Technology, Veterinary Faculty, Regional Campus of International Excellence "Campus Mare Nostrum", \\ University of Murcia, Espinardo, E-30071, Murcia, Spain \\ †Central Quesera Montesinos S.L., Calle Vereda Real s/n, 30520 Jumilla, Murcia, Spain \\ $\ddagger$ Food Science and Technology Department, Universitat Autónoma de Barcelona (UAB), 08193 Bellaterra (Cerdanyola del Valles), \\ Barcelona, Spain
}

\begin{abstract}
The applicability of a light backscatter sensor with a large field of view was tested for on-line monitoring of coagulation and syneresis in a goat cheese (Murcia al Vino) manufactured under industrial conditions. Cheesemaking was carried out concurrently in a $12-\mathrm{L}$ pilot vat and a 10,000-L industrial vat following the normal cheesemaking protocol. Cheese moisture, whey fat content, hardness, springiness, and adhesiveness were measured during syneresis. The results obtained show that cutting time is best predicted by considering the coagulation ratio at the inflection point and the percentage increase in the ratio during coagulation, with no need for the first derivative. The large field of view reflectance ratio provided good results for the prediction of moisture content, yield, hardness, springiness, and adhesiveness of the final cheese.
\end{abstract}

Key words: moisture, yield, cutting time, sensor

\section{INTRODUCTION}

Predictions of cutting time, moisture, and cheese yield are useful for adjusting technological procedures during cheesemaking and are therefore considered an appropriate tool for ensuring high-quality products and profitability. Formaggioni et al. (2008) reviewed the different predictive formulas proposed in the literature for calculating cheese yield, and Emmons et al. (1990) described the various predictive formulas of cheese moisture in the literature and developed new formulas, using an approach based on theoretical considerations concerning the distribution of solids and moisture in the different phases but under experimental conditions (Formaggioni et al., 2008).

Received March 23, 2012.

Accepted July 12, 2012.

${ }^{1}$ Corresponding author: silvia.rovira@um.es
Cutting time, moisture content, and cheese yield have been predicted by means of optical sensors, such as the CoAguLite fiber optic sensor (Reflectronics Inc., Lexington, KY) developed by Payne et al. (1997). The CoAguLite sensor is not only able to predict cheesemaking indices, such as cutting time and cheese yield, but it can also be used to develop algorithms of curd moisture and fat loss during milk coagulation. The sensor has been used to study (1) the effects of temperature, inocula, and $\mathrm{CaCl}_{2}$ concentrations in experimental conditions without applying all the manufacturing processing steps (Castillo et al., 2000, 2002, 2003); (2) a possible application during cheesemaking until cutting time; and (3) the ability to predict cheese yield, moisture, and fat contents in cow milk and under experimental conditions without applying all the processing steps involved in cheese production (Fagan et al., 2007d, 2008). Nevertheless, this sensor showed low applicability for predicting the above parameters after curd cutting. To improve the results observed, a light backscatter sensor with a large field of view (LFV) was developed as a prototype model and tested in experimental conditions using different milk protein and fat contents, firmness and protein ratio levels, and stirring speeds (Fagan et al., 2007b,c,d; Mateo et al., 2010). Its ability to predict whey production and fat content in whey at syneresis was confirmed, with the results being better than those obtained with the CoAguLite sensor. The same authors highlighted the importance of testing the LFV sensor under industrial conditions, following the processing steps involved in cheese manufacturing.

The LFV sensor has been used in different experimental designs. Until now, the factorial experimental designs carried out include 3 gel-cutting intensities, 3 curd-stirring speeds, 2 protein levels and fat:protein ratios, 4 milk fat levels, and, finally, 3 firmness levels, all using recombined milk (skim milk powder and distilled water) but not pasteurized cow or goat milk, as is used in industrial cheese manufacture. In each of those 
LFV sensor application experiments, stirring continued during syneresis, without taking into account the contribution of individual steps in the overall process, such as the pitching, washing, and cooking processes, which take place in many industrial manufacturing processes and that have a great effect on final cheese properties and yield (Mateo et al., 2010). In addition, different cutting programs have been tested for the application of this sensor in recombined milk (12\% TS; Mateo et al., 2009) without considering the variations involved in day-to-day production.

Only one study was found regarding the application of the LFV sensor that took into account the manufacturing processes involved in a common goat cheese variety. Rovira et al. (2011) applied the prototype LFV sensor for the on-line monitoring of fresh goat cheese during its manufacture on an experimental scale. These authors used the CoAguLite sensor as a reference to select suitable configuration details for the LFV sensor for this type of cheese and manufacturing design, finding the appropriate wavelengths to be 990, 1,000, and $1,010 \mathrm{~nm}$.

Unavoidable day-to-day variations are of great importance for the application of any prediction algorithm derived from the sensor and should be taken into account if the obtained results are to be directly transferred to industrial conditions. All preliminary prediction algorithms so far developed with the LFV sensor include sensor parameters that are difficult to measure in industrial conditions and by cheese makers in general.

The aim of this work was to apply the LFV prototype sensor under industrial processing conditions to a washed pressed goat cheese (Murcia al Vino), developing new algorithms for the prediction of cutting time, moisture, and cheese yield. Such a study is a necessary step if the LFV sensor is to be useful on an industrial scale.

\section{MATERIALS AND METHODS}

\section{Milk Source and Compositional Analysis}

The goat milk for cheese making was pasteurized in the Central Quesera Montesinos S.L (Murcia, Spain) dairy at $74.5^{\circ} \mathrm{C}$ for 15 to $20 \mathrm{~s}$ and was used immediately. The average values of milk composition (as analyzed by the suppliers) are shown in Table 1.

\section{Cheesemaking Procedure}

On 13 randomly chosen days, Murcia al Vino (a washed-curd, semihard, pressed cheese, with a cylindrical shape and a smooth rind; washed in red wine and ripened for $45 \mathrm{~d}$ ) goat cheeses weighing $500 \mathrm{~g}$ and 2 $\mathrm{kg}$ were manufactured in parallel at 2 different levels: in a $10,000-\mathrm{L}$ vat in the Central Quesera Montesinos S.L. dairy following existing standards concerning the manufacture of Protected Designation of Origin Murcia al Vino cheese, and in a 12-L pilot scale vat (Pierre Guerin Ibérica S.A., Burgos, Spain), respectively, following the same processing steps and using the same raw materials. The average values of cheese composition are shown in Table 1.

All steps carried out were those followed for Murcia al Vino cheese manufacture. Calcium chloride (Betelgeux, S. L., Gandía, Valencia, Spain) and starter were added to the milk. When the milk reached $33.3^{\circ} \mathrm{C}$, rennet $(50 \mathrm{~L}$ NG Reniplus, Caglio Star España S.A., Murcia, Spain) was added at $0.026 \mathrm{mg} / \mathrm{L}$.

The curd was cut (for $6 \mathrm{~s}$ ) and pitched (for $5 \mathrm{~min}$ ) 40 min after adding the rennet. A second cut lasting 10 min was carried out, followed by 2 series of pitchings (5 min) and stirrings (10 min). The next step corresponded to draining ( $15 \%$ of the initial amount of milk), before washing and heating the curd at $38^{\circ} \mathrm{C}$ in a simultaneous process that lasted 25 to 30 min (with an approximate temperature increase of $1^{\circ} \mathrm{C}$ every $5 \mathrm{~min}$ ). After heating, a series of stirring (10 min) and pitching $(5 \mathrm{~min})$ steps was carried out for $1 \mathrm{~h}$ until the $\mathrm{pH}$ decreased to 6.3. The curd was then molded, pressed for $2 \mathrm{~h}$, and introduced into a brine bath for $1 \mathrm{~d}$ and left to mature under controlled temperature and humidity conditions for $45 \mathrm{~d}$. Cheeses were immersed in red wine after $30 \mathrm{~d}$ of ripening and left to ripen for another $15 \mathrm{~d}$.

\section{On-Line Light Backscatter Monitoring Instrumentation}

Two sensors were coupled to the 12-L air-conditioned vat: the CoAguLite sensor (model 5, Reflectronics Inc.;

Table 1. Physicochemical composition of milk and cheese

\begin{tabular}{lr}
\hline Parameter & Mean $\pm \mathrm{SD}$ \\
\hline Milk & \\
Protein $(\mathrm{g} / 100 \mathrm{~mL})$ & $3.46 \pm 0.05$ \\
Fat $(\mathrm{g} / 100 \mathrm{~mL})$ & $4.76 \pm 0.22$ \\
$\mathrm{DM}(\mathrm{g} / 100 \mathrm{~g})$ & $13.30 \pm 0.02$ \\
$\mathrm{pH}$ & $6.77 \pm 0.01$ \\
Acidity $\left({ }^{\circ}\right.$ Dornic) & $13.96 \pm 0.33$ \\
Cheese & \\
Protein $(\mathrm{g} / 100 \mathrm{~g})$ & $23.52 \pm 0.97$ \\
DM $(\mathrm{g} / 100 \mathrm{~g})$ & $65.74 \pm 1.30$ \\
Fat $(\mathrm{g} / 100 \mathrm{~g})$ & $39.12 \pm 1.70$ \\
$\mathrm{pH}$ & $5.25 \pm 0.10$ \\
Hardness $(\mathrm{N})$ & $26.34 \pm 4.66$ \\
Springiness $(\mathrm{mm})$ & $7.31 \pm 1.12$ \\
Adhesiveness $(\mathrm{N} \cdot \mathrm{s})$ & $1.84 \pm 0.81$ \\
Cheese yield $(\mathrm{L} / \mathrm{kg})$ & $7.50 \pm 0.17$ \\
\hline
\end{tabular}


Table 2. Definition of parameters during coagulation and syneresis

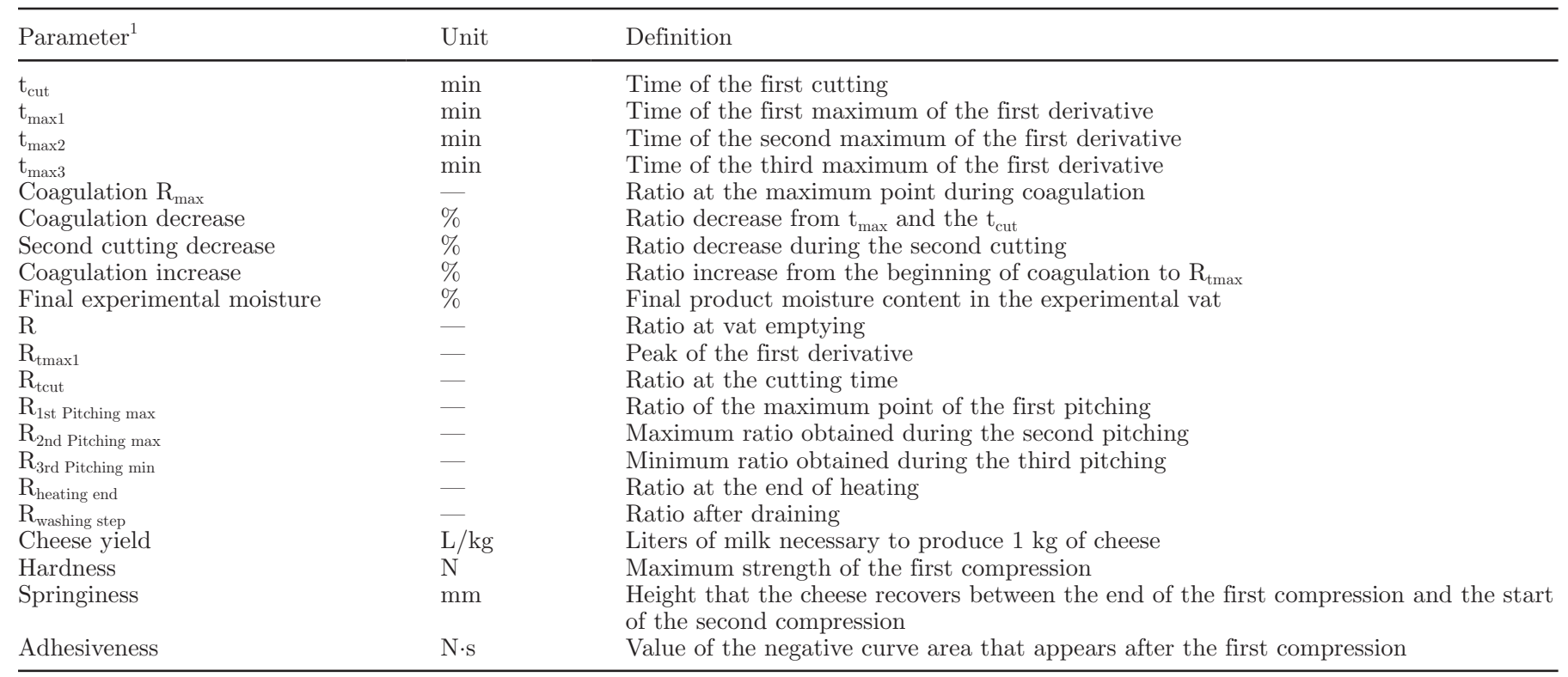

${ }^{1} \mathrm{R}=$ light backscatter (sensor) ratio.

Payne, et al., 1993), which measures at $880 \mathrm{~nm}$, and the LFV sensor (prototype, University of Kentucky, Lexington; Fagan et al., 2007c, 2008), which measures at wavelengths from 200 to $1,100 \mathrm{~nm}$. The light backscatter response from the 2 sensors was continuously monitored throughout the processing steps described (the same as those carried out in the industrial vat), from the time of rennet addition $\left(\mathbf{t}_{0}\right)$ to the end of syneresis, considered as the time when the vat began to be emptied. Response data were collected every 10 $\mathrm{s}$. The initial voltage $\left(\mathrm{V}_{0}\right)$ was calculated by averaging the first 4 data points obtained before rennet addition. The light backscatter ratio $(\mathbf{R})$, the first derivative $\left(R^{\prime}\right)$ of the light backscatter ratio profile, and time at the maximum ratio of the first derivative $\left(t_{\max }\right)$ were calculated as described by Fagan et al. (2007d). The second derivative $\left(\mathrm{R}^{\prime \prime}\right)$ was calculated in a similar manner by using 60 data points to smooth the $\mathrm{R}^{\prime \prime}$ profile (Fagan et al., 2007b).

The LFV prototype sensor is related to curd particle size. The light emerging from the fiber optic cable is processed in the spectrometer, allowing identification of differences in intensity throughout cheesemaking as described by Fagan et al. (2007a). The optical configuration details and the optical parameters derived ( $t_{\max }$, $t_{\text {cut }}, R_{\text {max }}$, and $R_{\text {cut }}$, defined in Table 2) were as described by Fagan et al. (2007a, 2008). The sensor response at $990 \mathrm{~nm}$ was used in this study (as determined in previous studies by Rovira et al., 2011). The sensor provided measurements every $100 \mathrm{~ms}$ and each spectrum was derived from 100 sensor scans. The spectrum was automatically processed every $10 \mathrm{~s}$. The voltage values for the first $14 \mathrm{~s}$ of data were averaged within each waveland $\mathrm{V}(\mathrm{w})$ to calculate initial voltage $\left[\mathrm{V}_{0}(\mathrm{w})\right]$. The light backscatter ratio for the LFV sensor $\left(\mathrm{R}_{\mathrm{LFV}}\right)$ and $t_{\max }$ was obtained as described by Fagan et al. (2008).

Several light backscatter parameters were derived from the response of both the LFV and CoAguLite sensors during coagulation and syneresis (see Table 2).

\section{Chemical and Texture Analyses}

Seven samples were collected from both the pilot and industrial vats at the following time points: at the first $\left(t_{1}\right)$ and second $\left(t_{2}\right)$ cuts, before washing $\left(t_{3}\right)$, after washing $\left(t_{4}\right)$, at the end of heating $\left(t_{5}\right)$, at the second pitching $\left(\mathrm{t}_{6}\right)$, and before molding $\left(\mathrm{t}_{7}\right)$.

Curd and whey samples were separated using a dairy cloth. For moisture content, grated cheese samples were dried to constant weight according to ISO (1997).

A texture profile analysis was carried out using a QTS-25 texture analyzer (Brookfield CNS Farnell, Borehamwood, UK) equipped with a load cell of $25 \mathrm{~kg}$ and Texture Pro V. 2.1 software (Brookfield CNS Farnell). For texture profile analysis, 4 cube-shaped samples $\left(1 \mathrm{~cm}^{3}\right)$ were cut from a rindless cheese, wrapped in aluminum foil, and equilibrated at $20^{\circ} \mathrm{C} \pm 0.5^{\circ} \mathrm{C}$ for 3 $\mathrm{h}$ before testing. The testing conditions were as follows: $20^{\circ} \mathrm{C}$ (room temperature); 2 consecutive cycles of $50 \%$ compression; cross-head constant speed of $30 \mathrm{~mm} / \mathrm{min}$; and a trigger point of $0.05 \mathrm{~N}$. Texture variables, hardness $(\mathrm{N})$, springiness $(\mathrm{mm})$, and adhesiveness $(\mathrm{N} \cdot \mathrm{s})$, were calculated as described by Bourne (1978). Five measurements per sample were made. 


\section{Testing a Suitable Algorithm for Moisture Content Prediction}

To test whether moisture content could be predicted in an appropriate way by algorithm IX, 10 additional cheesemaking trials were carried out in the pilot-scale vat in the same way as described in the Cheesemaking Procedure section.

\section{Control of Moisture by a Selected Prediction Algorithm}

To test whether the moisture content at vat emptying could be controlled by the algorithm selected, another 4 cheesemaking trials were carried out in the same way as described above, but selecting 2 desired final moisture percentages ( $54 \%$ and $57 \%$ ). This was made possible by solving the parameter ratio from the equation for each selected moisture content:

$$
\begin{gathered}
\mathrm{M}=85.22 \mathrm{R}_{\text {heating end }}+35.66 \mathrm{R}, \\
{\left[\mathrm{R}=\mathrm{M}-\left(85.22 \mathrm{R}_{\text {heating end }}\right) / 35.66\right],}
\end{gathered}
$$

where $\mathrm{M}=$ moisture content, $\mathrm{R}_{\text {heating end }}=$ ratio at the end of heating, and $\mathrm{R}=$ ratio at vat emptying. Once solved, vat emptying was carried out when the ratio reached the value determined for each moisture content $(54 \%$ or $57 \%)$.

\section{Statistical Analysis}

Statistical treatment of the data was performed by SPSS v15.0 (2006, SPSS Ibérica S.L.U., Madrid, Spain). One-way ANOVA was used to determine significant differences between the pilot and the industrial vat. Multivariate linear regression analysis fitted to several regression models was performed to develop the prediction algorithms.

\section{RESULTS AND DISCUSSION}

\section{Comparison of Pilot Plant and Industrial Cheese Vat}

The prototype LFV sensor is currently not available for coupling to industrial vats; hence, it was necessary to determine whether differences exist in the physicochemical and yield properties of cheeses made in the pilot and industrial vats following the same manufacturing process and with the same raw materials and ingredients. After applying an ANOVA test, no differences were observed in moisture content or whey fat content, although significant differences were observed for cheese yield $(P$-values $=0.28,0.13$, and 0.04 , re- spectively). These data confirm an adequate degree of parallelism for the pilot scale and industrial vats. Using the same raw materials, ingredients, and processes on both production scales allowed us to obtain a final product that meets the same specifications. This allows a preliminary conclusion that the algorithms developed could be useful on an industrial scale in the manufacture of this cheese. As no differences were observed between vats, any further results obtained for the pilot scale vat should be applicable to industrial-scale cheesemaking.

\section{Development of Algorithms for Predicting Cutting Time}

One of the most important applications of the LFV sensor in the manufacturing process is to predict different cheesemaking indices that affect final product quality, such as cutting time. Based on the results for the sensor response during coagulation in the 13 cheese manufacturing processes considered, 8 models were obtained for prediction of cutting time (Table 3). The first model corresponded to the reference prediction algorithm, obtained using the data derived from the CoAguLite sensor response. This sensor has demonstrated its suitability for predicting cutting time (Castillo et al., 2000; Fagan et al., 2007c) in goat milk during coagulation and was therefore used as a reference for comparing the other algorithms developed. Model II was similar to the reference equation, with the same regression coefficient and similar equation coefficient $\left(\beta_{1}\right)$ and standard error of prediction (SEP) values, which demonstrates the ability of the LFV sensor to predict cutting time with the same accuracy as the reference sensor.

One of the cutting time prediction models developed by Castillo et al. (2006a) using the reference sensor CoAguLite $\left(t_{\text {cut }}=\beta_{0}+\beta_{1} t_{2 \max 2}\right)$ included a significant intercept $\left(\beta_{0}\right)$ and a significant time-based parameter $\left(\mathrm{t}_{2} \max _{2}\right)$. However, this model had a higher SEP (14.7 min) than the prediction models developed here, as can be seen in Table 3. The inclusion of other parameters in the prediction models described by the same research group improved the statistical results (Castillo et al., 2006b), which must still be considered less appropriate $(\mathrm{SEP}=7.91)$ than the results obtained in this study (maximum SEP $=4.80$ ). Moreover, previous models proposed by Payne et al. (1998; $\mathrm{t}_{\text {cut }}=\beta_{0}+\beta_{1 \mathrm{tmax}}+$ $\left.\beta_{2} R_{\max }^{\prime}, \mathrm{SEP}=15.1\right)$ and Crofcheck et al. (1999; $\mathrm{t}_{\text {cut }}$ $\left.=\beta_{1 \text { tmax }}+\beta_{2} \mathrm{~S}, \mathrm{SEP}=23.7\right)$, included $\mathrm{t}_{\max }$, as did this study, but in both cases this parameter was related to others, leading to a much greater error than that obtained by the LFV sensor in this study.

Although algorithm III had the same regression coefficient $\left(\mathrm{R}^{2}=0.96\right)$ but lower $\mathrm{SEP}(1.21 \mathrm{~min})$ than 
Table 3. Prediction of cutting time $\left(t_{\text {cut }}\right)$ by large field of view sensor during goat cheese manufacture ${ }^{1}$

\begin{tabular}{|c|c|c|c|c|c|}
\hline Model $^{2}$ & Equation $^{3}$ & df & $\beta_{1}$ & $\mathrm{R}^{2}$ & $\mathrm{SEP}(\min )$ \\
\hline Ref. & $\mathrm{t}_{\mathrm{cut}}=\beta_{1} \mathrm{t}_{\max }$ & 12 & $3.42^{* * *}$ & 0.96 & 1.40 \\
\hline II & $\mathrm{t}_{\text {cut }}=\beta_{1} \mathrm{t}_{\max 1}$ & 12 & $3.52^{* * *}$ & 0.96 & 1.44 \\
\hline III & $\mathrm{t}_{\mathrm{cut}}=\beta_{1} \mathrm{t}_{\max 2}$ & 12 & $2.58^{* * *}$ & 0.96 & 1.21 \\
\hline IV & $\mathrm{t}_{\text {cut }}=\beta_{1} \mathrm{t}_{\max 3}$ & 12 & $1.34^{* * *}$ & 0.99 & 0.22 \\
\hline V & $\mathrm{t}_{\mathrm{cut}}=\beta_{1}$ Coagulation decrease & 12 & $1.69^{* * *}$ & 0.86 & 4.80 \\
\hline VI & $\mathrm{t}_{\mathrm{cut}}=\beta_{1} 2$ nd cutting decrease & 12 & $0.82^{* * *}$ & 0.99 & 0.40 \\
\hline VII & $\mathrm{t}_{\mathrm{cut}}=\beta_{1}$ Coagulation increase & 12 & $6.61^{* * *}$ & 0.99 & 3.83 \\
\hline VIII & $\mathrm{t}_{\text {cut }}=\beta_{1}$ Coagulation $\mathrm{R}_{\max }$ & 12 & $38.24^{* * *}$ & 0.99 & 0.02 \\
\hline
\end{tabular}

algorithm II $\left(\mathrm{R}^{2}=0.96, \mathrm{SEP}=1.44 \mathrm{~min}\right)$, the latter should be considered more suitable because this second model is closer to the reference model.

Factor $t_{\max 3}$ of model IV was not observed on all cheesemaking days or in previous models. Hence, algorithm IV can be dismissed as a tool for predicting cutting time, because an algorithm must be appropriate for all cheesemaking processes.

We studied the possibility of predicting cutting time from other parameters derived from the LFV sensor response (Table 3). All algorithms demonstrated potential for use in cheesemaking as they showed high regression coefficients and a greater significance level $(P<0.0001)$ than models reported by other authors using the reference sensor CoAguLite (Payne et al., 1998; Crofcheck et al., 1999; Castillo et al., 2006a) in other types of milk.

Models V, VI, and VII used the ratio percentage decrease involved during coagulation and after the second cutting, and the increase in the ratio percentage during coagulation. The regression coefficients from models VI and VII were high (both $\mathrm{R}^{2}=0.99$ ), although that of model $\mathrm{V}$ was slightly lower $\left(\mathrm{R}^{2}=0.86\right)$. Models $\mathrm{V}$ and VII had higher SEP values (4.80 and $3.83 \mathrm{~min}$, respectively) than those observed for model VI (0.40 min), and so their potential value for predicting cutting time was lower.

Model VIII had a SEP very close to zero (0.02 min). The parameter introduced in this model (ratio at the highest point of coagulation) is an appropriate parameter for use in industrial manufacture as it is easier to identify than $t_{\max }$ (time to reach the maximum of the first derivative), because it is obtained directly from the sensor, rather than by applying the first derivative or other mathematical calculations.

The graphs displayed in Figure 1 plot the real values measured in this study against those predicted by the different models developed and included in Table 3. For prediction of cutting time (Figure 1), models IV, VI,
VII, and VIII showed the highest regression coefficients $\left(\mathrm{R}^{2}>0.99\right)$, but the best linear trends were observed in models III and VIII (Figure 1). Model VII should be avoided because it showed a downward trend, which is not appropriate (lower real cutting times should be associated with lower predicted cutting times, not higher).

\section{Development of Algorithms to Predict Cheese Moisture Content}

Table 4 includes all the algorithms developed to predict cheese moisture content, which, as previously stated, is very important in cheese making (Dejmek and Walstra, 2004). In the models, explanatory variables were obtained directly or derivatively from the LFV sensor response. The first 3 models (I, II, and III) were derived from coagulation parameters $\left(t_{\max 1}\right.$, $R_{\text {max }}$, and $R_{\text {tcut }}$ ), whereas the other models included variables from syneresis, which have not previously been considered $\left(\mathrm{R}_{1 \text { st Pitching max }}, \mathrm{R}_{\text {2nd Pitching max }}, \mathrm{R}_{3 \text { rd Pitch- }}\right.$

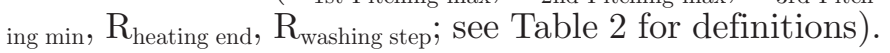
These parameters were defined considering that, for moisture standardization, it is necessary to consider all processes involved in cheese manufacture because the processes may influence differences between cheese batches, leading to possible differences in the final product and thus in cheese yield. All $\beta$ values obtained were highly significant $(P<0.001)$. The best regression coefficient from the first 3 algorithms corresponded to model III $\left(\mathrm{R}^{2}=0.98\right)$, which also showed the lowest SEP $(0.53 \%)$. Models IV, V, and VI attempt to predict cheese moisture content based on the peak of the LFV sensor observed at curd pitching, particularly during the first 3 pitchings. The highest regression coefficient for these 3 models was obtained in model IV $\left(\mathrm{R}^{2}=\right.$ $0.99)$, which showed the lowest SEP (0.39). In addition, models V and VI showed appropriate $\mathrm{R}^{2}$ coefficients and SEP values and should not necessarily be dis- 
Model II

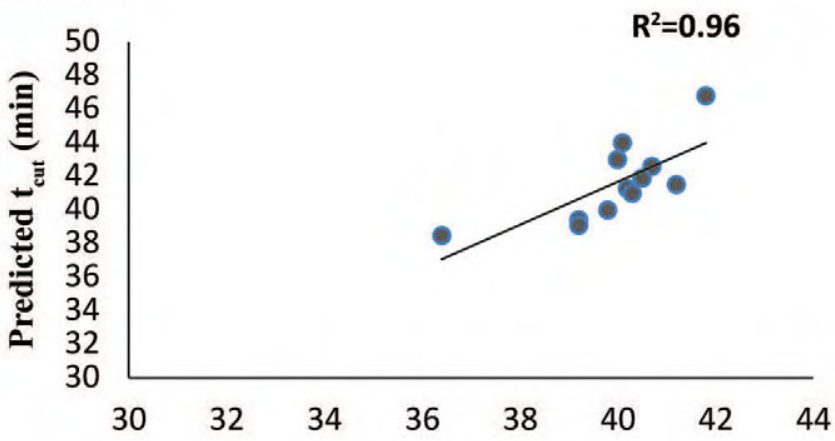

Model IV

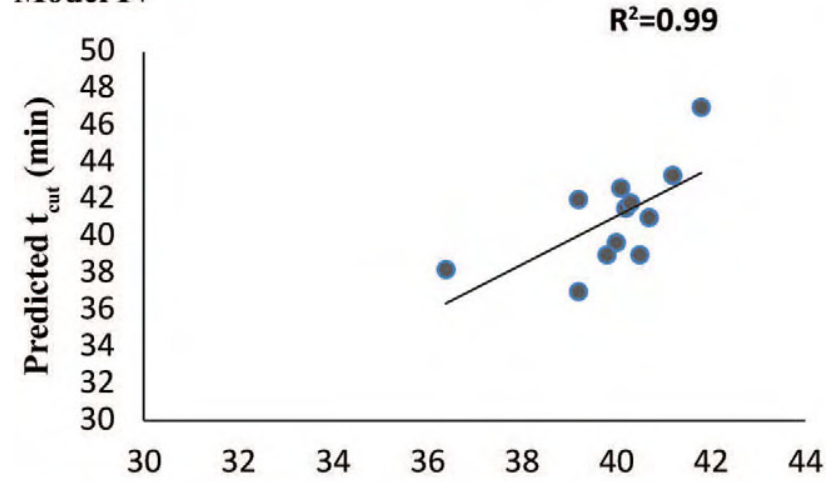

Model VI

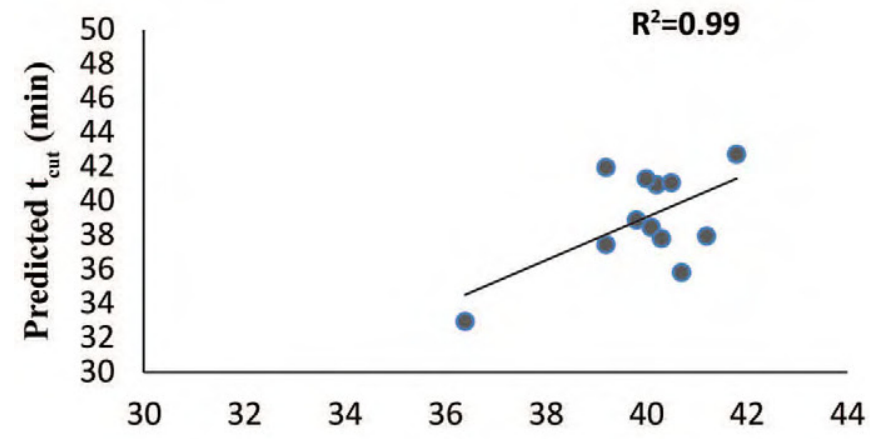

Model VIII

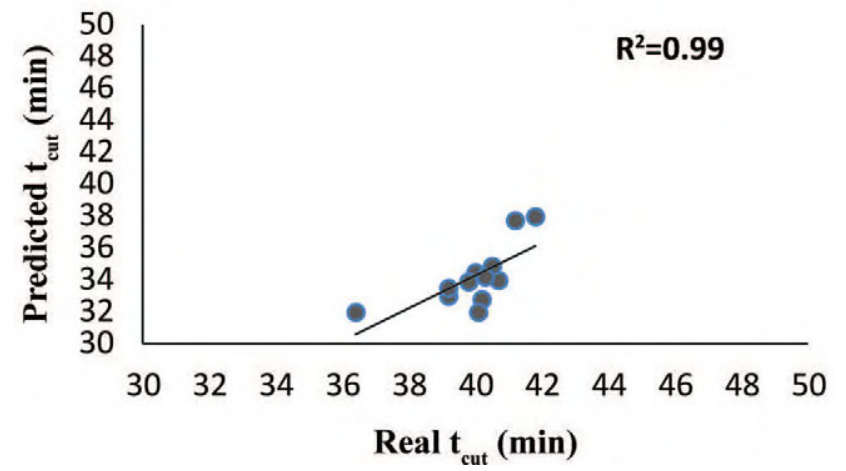

\section{Model III}
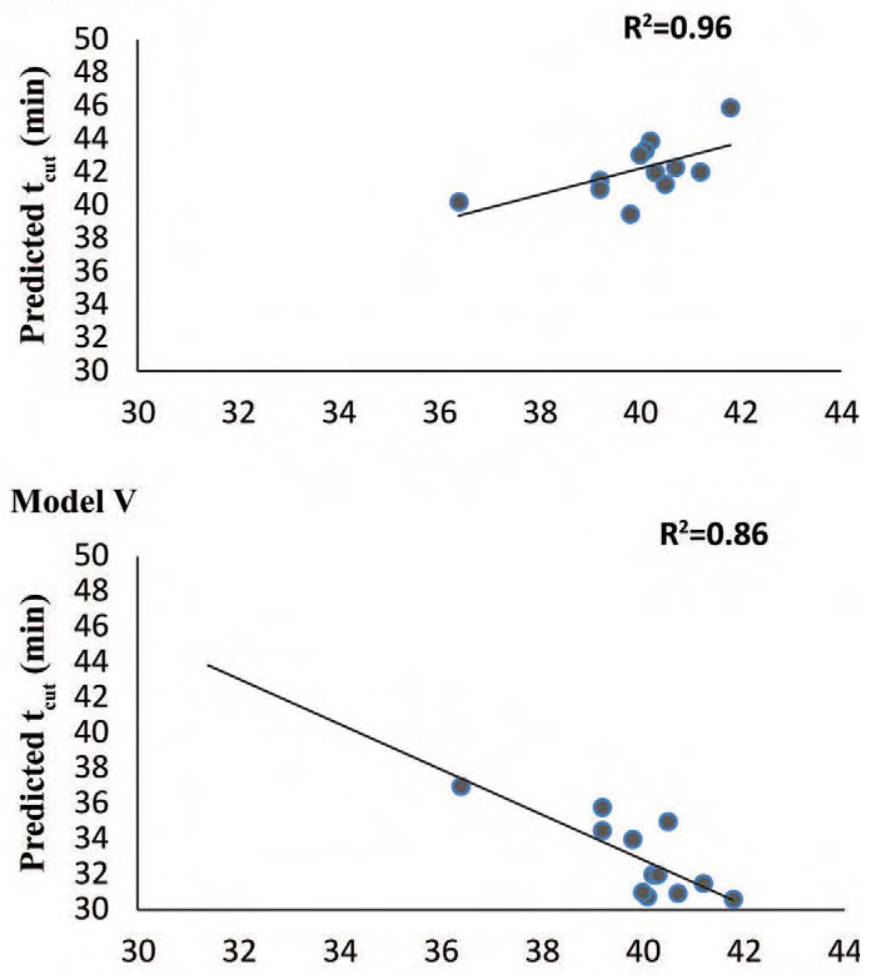

\section{Model VII}

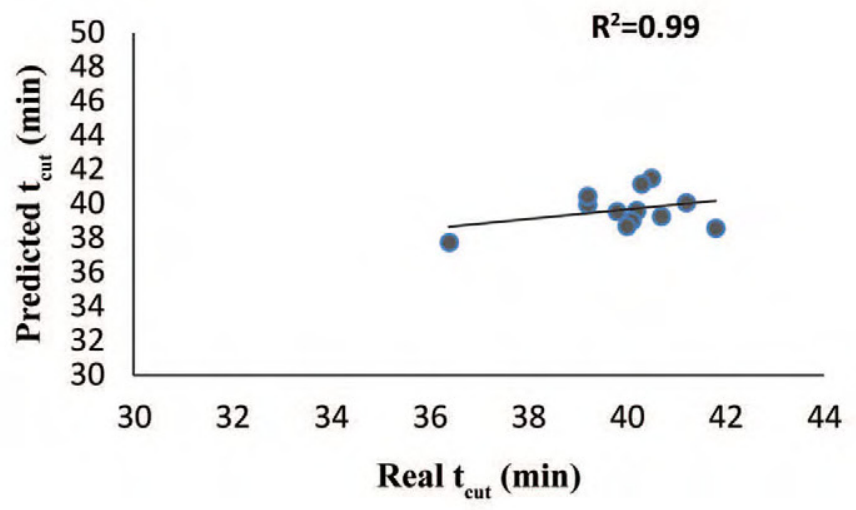

Figure 1. Measured versus predicted cutting time $\left(\mathrm{t}_{\mathrm{cut}}\right)$; representation of the linear trend from the cutting time models detailed in Table 3 . Color version available in the online PDF. 
Table 4. Prediction of goat cheese moisture content and cheese yield by large field of view sensor ${ }^{1}$

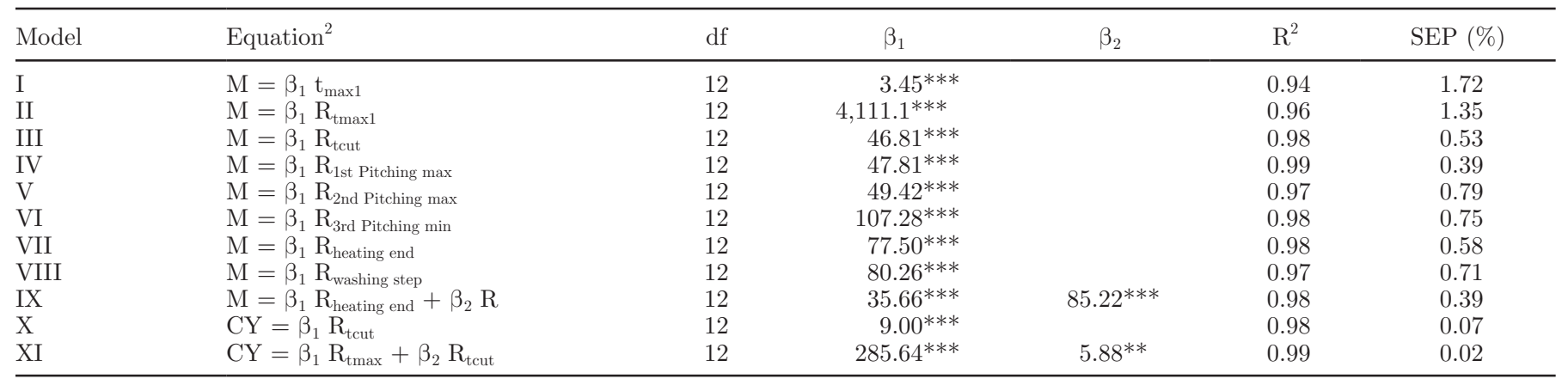

${ }^{1} \beta_{1}$ and $\beta_{2}=$ equation coefficients; $\mathrm{R}^{2}=$ regression coefficient; SEP = standard error of prediction.

${ }^{2} \mathrm{M}=$ moisture content in cheese; $\mathrm{CY}=$ cheese yield; see Table 2 for definition of other terms.

$* * P<0.01 ; * * * P 0.001$

carded. Finally, models VII, VIII, and IX, which used the ratio at the end of heating, the ratio at washing, and the ratio at the end of heating together with the ratio at vat emptying, respectively, showed high regression coefficients $(0.98,0.97$, and 0.98 , respectively) and low SEP values $(0.58,0.71$, and $0.39 \%$, respectively) and could be considered suitable for predicting cheese moisture content during the manufacture of this type of (washed-curd) cheese.

Fagan et al. (2007b,c,d) reported the potential of the LFV sensor for monitoring milk coagulation and syneresis, and demonstrated the potential of this prototype sensor to predict curd moisture content. However, the first prediction models developed by these authors were limited by the small data set used but were improved by Fagan et al. (2008). The last and best curd moisture prediction model developed by these authors in cow milk under experimental conditions (after curd cutting, the curd was continuously stirred for $85 \mathrm{~min}$ ) included 4 parameters - temperature, time to reach the first maximum of the ratio $\left(\mathrm{t}_{\max }\right)$, milk fat content, and fat protein ratio of milk), which differ markedly from the parameters selected for our study. The factors included in the models (III, IV, V, VI, VII, VIII, and IX) shown in Table 4 have not previously been reported and provided better $\mathrm{R}^{2}$ and SEP values that those obtained for the model developed by Fagan et al. $\left(2008 ; \mathrm{R}^{2}=0.94\right.$, $\mathrm{SEP}=1.46$ ).

The significance of the parameters included in this prediction model lies in the effect of the technical steps on the physicochemical properties of the final product. The retention of water is attributed, among other causes, to the relative rigidity and restructuring of the protein matrix derived from some of the technical steps carried out in cheesemaking, such as pitching of the curd after stirring, a step known to be significant in the prediction of cheese moisture content.
As regards the models for moisture content prediction (Figure 2), the number of values represented (n $=13$ ) is lower than the number considered by Mateo et al. (2010); hence, the $\mathrm{R}^{2}$ are higher (0.94-0.99) than those of Mateo et al. (2010; 0.65-0.96), who used the LFV sensor over a broad spectrum of 189 to 1,100 $\mathrm{nm}$. Model IV shows the most suitable tendency and prediction coefficients, which emphasizes the importance of considering the mechanical steps in predicting final moisture content because this model takes into account the first pitching process involved during the manufacture of Murcia al Vino cheese. Other cheese moisture prediction models do not use this type of parameter (e.g., $\left.R_{\text {pitching, }} \mathrm{R}_{\text {heating end }}\right)$. Model III should be avoided because lower real moisture content should be associated with lower predicted moisture content, and a downward trend is not appropriate. Moreover, model VIII should be avoided because it shows a very low slope, which reflects a lower match between the real and predicted values.

\section{Development of Algorithms to Predict Cheese Yield}

Table 4 shows the different prediction models for cheese yield, obtained by using optical parameters. The 2 models developed provided significant values for $\beta_{1}(P$ $<0.001)$ and $\beta_{2}(P<0.01)$, high correlation coefficients (0.98 and 0.99 for models $\mathrm{X}$ and XI, respectively), and low SEP values (0.07 and $0.02 \%$, respectively), which underlines their ability to predict cheese yield with great precision during goat cheese manufacture, although goat cheeses usually involve more intrinsic physicochemical variations than most of the cheeses derived from cow milk.

Guo et al. (2004) stated that yield is related to chemical composition, including moisture. Our results confirm that optical parameters derived from the LFV 
Model I

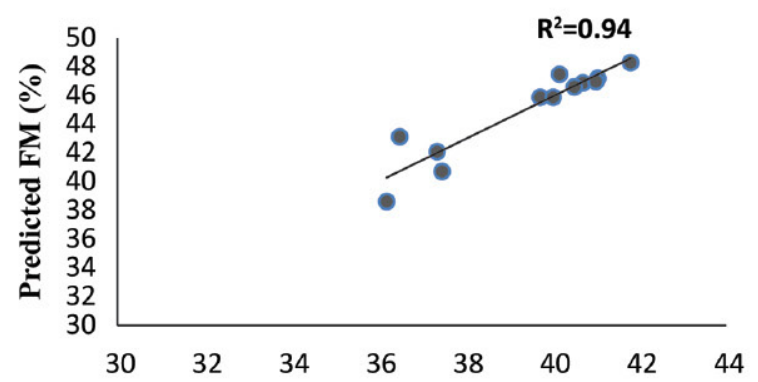

Model III

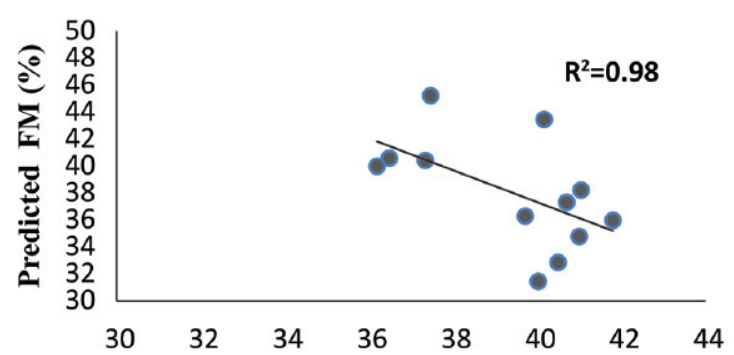

Model V

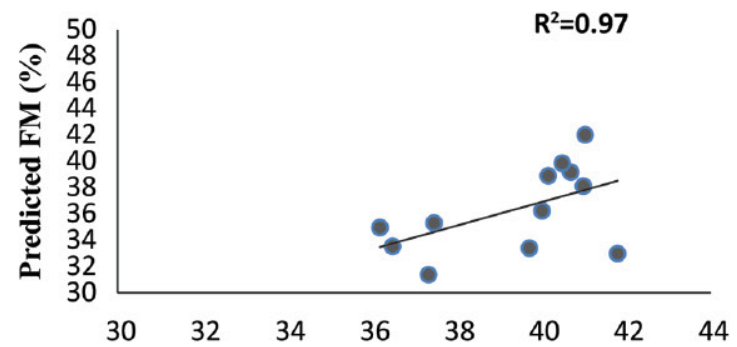

Model VII

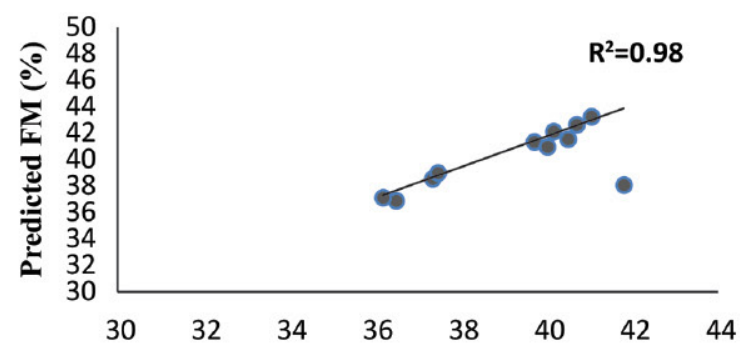

Model IX

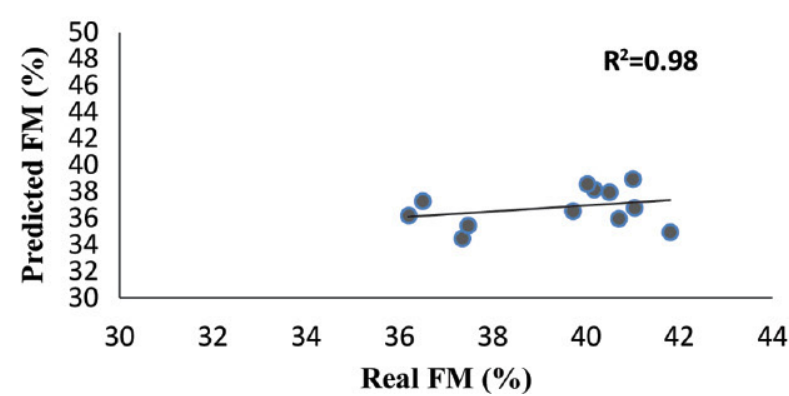

\section{Model II}

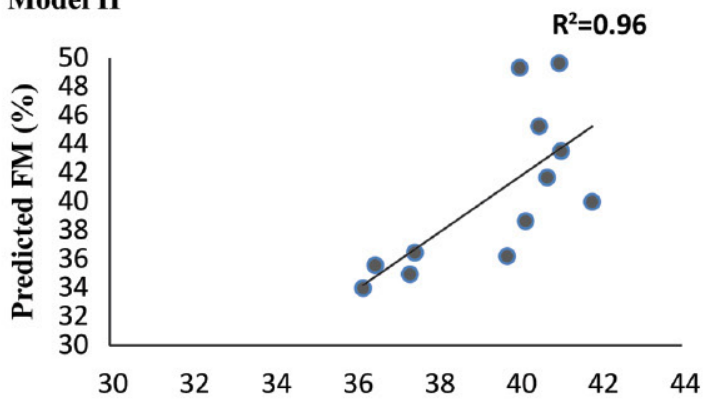

Model IV

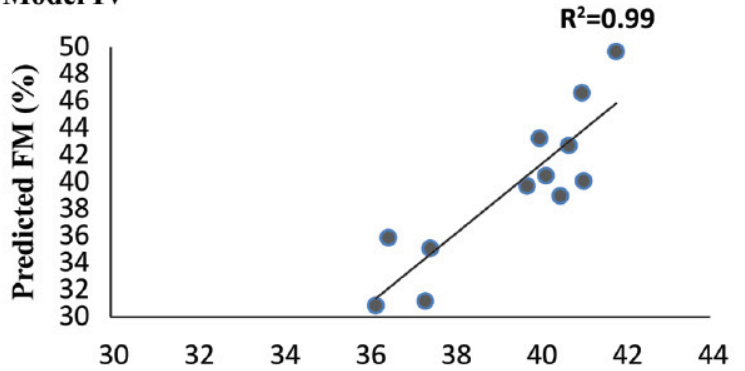

Model VI

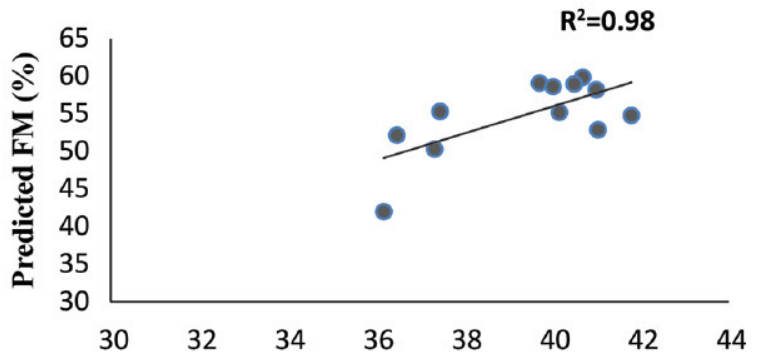

\section{Model VIII}

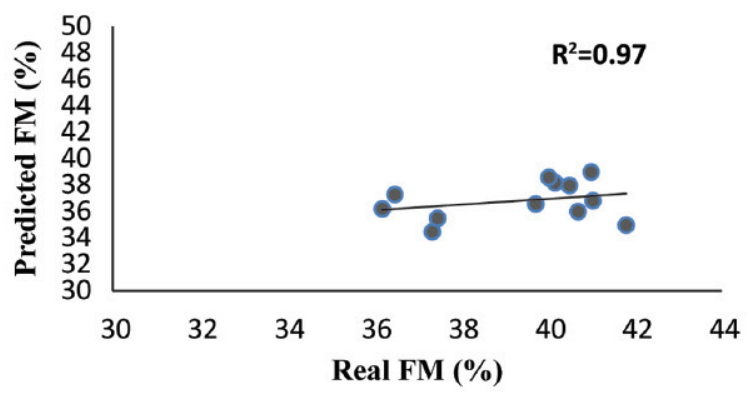

Figure 2. Measured versus predicted final moisture (FM) content of cheese; representation of the linear trend from the final moisture content models detailed in Table 4 . Color version available in the online PDF. 
sensor can be considered a valid tool for predicting cheese yield (without the need to consider chemical parameters or moisture content) because the regression coefficients obtained were greater than those presented by Guo et al. (2004; $\mathrm{R}^{2}=0.81$, no $\mathrm{SEP}$ reported) in fresh goat milk cheese using chemical parameters. Our results are also better than those of Fagan et al. (2008) in cow milk during 85 min of stirring; those authors predicted cheese yield in experimental conditions by taking into account milk temperature, total solids contents, and the average ratio values for the first $15 \mathrm{~min}$. This provided a lower regression coefficient and a higher SEP value (0.90 and 0.95 , respectively), although the experimental conditions were carefully controlled to avoid variations.

Figure 3 depicts the linear trend obtained for the prediction of cheese yield during cheese making. The predicted and real values obtained were in the same range, although the range was slightly wider in model XI. Visually, no differences were observed between the slopes of the linear trends shown in Figure 3. Nevertheless, the trend observed was better than that reported by Fagan et al. (2008) in cow milk in experimental conditions and during a single stirring; Fagan et al. (2008) reported a visibly lower slope and a lower $\mathrm{R}^{2}$ coefficient (0.90), even though they considered chemical parameters. As can be observed, the LFV sensor allows prediction of moisture content during syneresis although different mechanical steps are involved. This is extremely important for the cheese maker as knowledge of moisture content allows profitability to be calculated at any time.

\section{Development of Algorithms for Predicting the Textural Parameters of Cheese}

Table 5 shows the models developed to predict textural parameters such as hardness, springiness, and adhesiveness in the final product. All models had highly significant $\beta$ values $(P<0.001)$. The first 3 models (I, II, and III) predicted cheese hardness, with high $\mathrm{R}^{2}$ values of $0.96,0.89$, and 0.94 , respectively. Model I can be considered the most appropriate for predicting this parameter as it had the lowest SEP $(0.02 \mathrm{~N})$ and the highest $\mathrm{R}^{2}$ value. The following 3 models (IV, V, and VI) were developed to predict springiness. The regression coefficients for these models were also high (0.95, 0.96 , and 0.89 , respectively). For prediction of springiness, model IV was the most appropriate as it showed the lowest SEP $(0.13 \mathrm{~mm})$. This model, together with model I, which best predicted cheese hardness, included the parameter ratio at cutting time $\left(\mathrm{R}_{\text {tcut }}\right)$ in the algorithm. This highlights the relation between the corresponding $\mathrm{R}_{\text {tcut }}$ and accurate prediction of the results.
The last 3 models (VII, VII, and IX) shown in Table 5 were used to calculate final cheese adhesiveness. The regression coefficients were lower than those seen in the algorithms for predicting the other 2 texture parameters. The lowest $\mathrm{R}^{2}$ was observed in model IX (0.76) and the highest in model VII (0.82). The lowest SEP value was that of model VII $(0.02 \mathrm{~N} \cdot \mathrm{s})$, so this model was considered the most appropriate for predicting cheese adhesiveness. The $R_{\text {tcut }}$ derived from the LFV sensor showed great potential for predicting all 3 texture parameters. This variable, with its low SEP and high regression coefficients, was best suited to this task.

Fagan et al. (2007c) studied the application of midinfrared spectroscopy for predicting sensory properties, comparing this technique with other recently proposed techniques: descriptive sensory analysis by a trained panel, texture profile analysis, near-infrared spectroscopy, and compression/texture profile analysis. The textural parameters most closely related to those from this study were firmness, chewiness, and fragmentability. These sensory attributes were analyzed both by sensory and mid-infrared spectroscopy to establish a relation between both sets of results. The best $R^{2}$ values obtained for the prediction of these textural param-

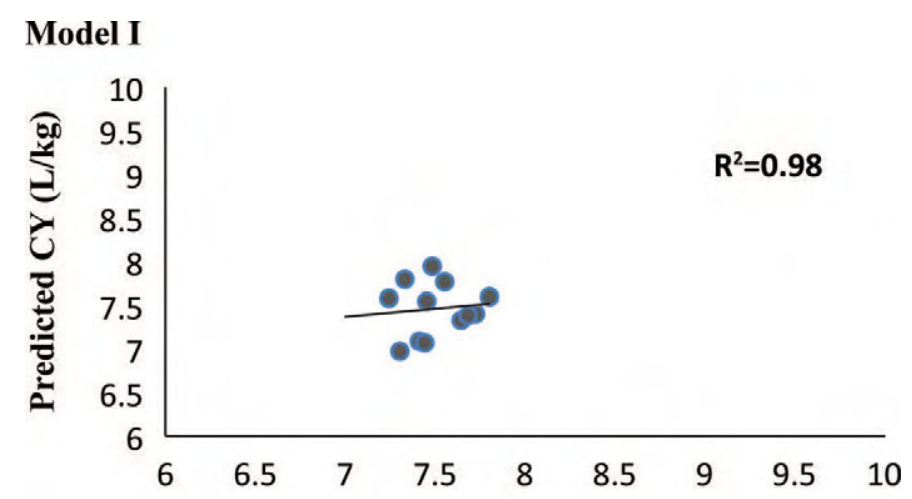

Model II

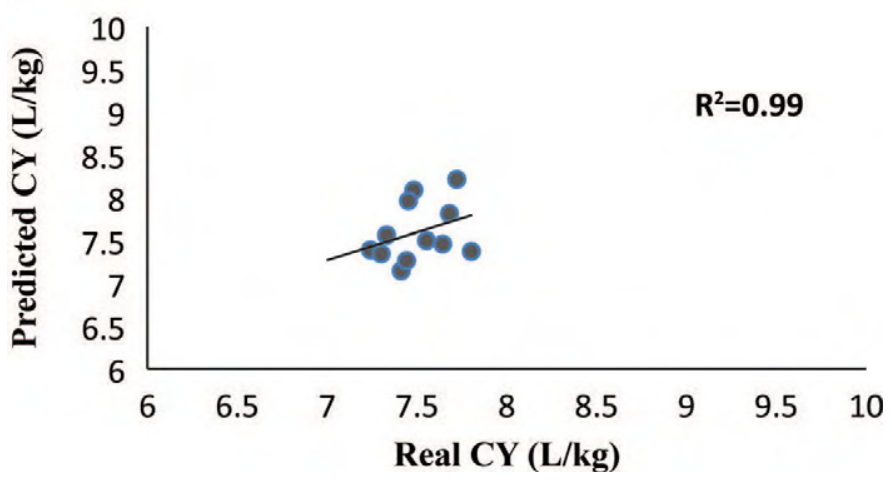

Figure 3. Measured versus predicted cheese yield (CY); representation of the linear trend from the cheese yield models detailed in Table 4. Color version available in the online PDF. 
Table 5. Prediction of textural parameters by large field of view sensor ${ }^{1}$

\begin{tabular}{|c|c|c|c|c|c|}
\hline Model & Equation $^{2}$ & $\mathrm{df}$ & $\beta_{1}$ & $\mathrm{R}^{2}$ & SEP \\
\hline I & $\mathrm{H}=\beta_{1} \mathrm{R}_{\mathrm{tcut}}$ & 12 & $32.14^{* * *}$ & 0.96 & $0.02 \mathrm{~N}$ \\
\hline II & $\mathrm{H}=\beta_{1} \mathrm{R}_{\mathrm{tmax}}$ & 12 & $2,750.68^{* * *}$ & 0.89 & $1.45 \mathrm{~N}$ \\
\hline III & $\mathrm{H}=\beta_{1} \mathrm{t}_{\max }$ & 12 & $2.39^{* * *}$ & 0.94 & $0.73 \mathrm{~N}$ \\
\hline IV & $\mathrm{S}=\beta_{1} \mathrm{R}_{\text {tcut }}$ & 12 & $8.71^{* * *}$ & 0.95 & $0.13 \mathrm{~mm}$ \\
\hline V & $\mathrm{S}=\beta_{1} \mathrm{R}_{\mathrm{tmax}}$ & 12 & $777.23^{* * *}$ & 0.96 & $0.44 \mathrm{~mm}$ \\
\hline VI & $\mathrm{S}=\beta_{1} \mathrm{t}_{\max }$ & 12 & $0.63^{* * *}$ & 0.89 & $0.41 \mathrm{~mm}$ \\
\hline VII & $\mathrm{A}=\beta_{1} \mathrm{R}_{\mathrm{tcut}}$ & 12 & $2.20^{* * *}$ & 0.82 & $0.02 \mathrm{~N} \cdot \mathrm{s}$ \\
\hline VIII & $\mathrm{A}=\beta_{1} \mathrm{R}_{\mathrm{tmax}}$ & 12 & $189.04^{* * *}$ & 0.80 & $0.10 \mathrm{~N} \cdot \mathrm{s}$ \\
\hline IX & $\mathrm{A}=\beta_{1} \mathrm{t}_{\max }$ & 12 & $0.16^{* * *}$ & 0.76 & $0.07 \mathrm{~N} \cdot \mathrm{s}$ \\
\hline
\end{tabular}

eters were 0.94, 0.93, and 0.96 for firmness, chewiness, and fragmentability, respectively, which are higher than those obtained in the current study. However, they correspond to different textural parameters and different analytical tools, which cannot be compared with those addressed in this study.

As regards the models used for textural parameter prediction (Figure 4), the parameter hardness provided the best prediction results, with the most appropriate trend, although the slopes obtained for this parameter were lower than those observed for springiness, which showed better $\mathrm{R}^{2}$ coefficients. Both could be adequately predicted by the LFV sensor. In this case, models III (hardness) and I and III (springiness) should be avoided because they showed a downward trend, which is not appropriate for prediction purposes.

\section{Testing the Suitable Algorithm for Moisture Content Prediction}

As can be observed in Table 4, the model showing the lowest SEP value for curd moisture prediction was model IX. This equation was developed using the mean of the ratio during the last $5 \mathrm{~min}$ of heating and the ratio at vat emptying. Model IV presented a SEP value of 0.39 and a higher $\mathrm{R}^{2}$ than model IX, but did not take account for the manufacturing steps after the first pitching. Therefore, taking into account the lowest SEP, the adequate $\mathrm{R}^{2}$, and the fact that the equation parameters included all the manufacturing processes from coagulation to vat emptying, model IX was selected.

Ten cheese productions were carried out to test the suitability of this selected equation. As can be observed in Table 6, the corresponding ratio at the end of heating barely differentiated between cheese batches, whereas the ratio at vat emptying varied, as did curd moisture. This fact highlights the usefulness of this sensor for predicting (with the selected algorithm) day-to-day production differences in moisture at vat emptying, with a mean SEP of $5.38 \%$, which is lower than the er- ror range (7-15\%) usually obtained in the industry for the moisture content of different batches of the same cheese variety.

\section{Control of Moisture by a Prediction Algorithm}

Cheese characteristics result from a variety of physicochemical changes that occur during ripening, principally through glycolysis, proteolysis, and lipolysis. Therefore, proper monitoring and control during ripening is of great importance. Approaches to control these changes during ripening should include critical compositional factors during manufacture. Standardizing curd moisture at vat emptying, before ripening, could reduce costs and improve efficiency. Variations in curd moisture during manufacturing are related to differences in the final product's moisture and yield, which explains efforts by cheese makers to improve and systematize curd moisture before ripening. Delaying or bringing forward curd vat emptying was related to differences in curd moisture and so can be considered a good tool for standardization of curd moisture.

As seen in Table 7, 2 curd moisture percentages were selected by the cheese maker ( 54 and $57 \%$ are known to be the most appropriate moisture percentages to obtain the desired cheese features and an appropriate cheese yield) to determine whether the sensor was useful for controlling curd moisture. Taking into account equation IX from Table 4, and solving the ratio from this equation, we obtained $\mathrm{R}=\mathrm{M}-\left(85.22 \mathrm{R}_{\text {heating end }}\right) / 35.66$. During manufacture, once $R_{\text {heating end }}$ is known, the appropriate ratio $(\mathrm{R})$ to obtain the desired moisture content (M) can be obtained. Vat emptying is carried out when the ratio reaches the corresponding value for each moisture content (54 and 57\%). This pilot-plant design and procedure for controlling moisture content has not been applied previously and thus we cannot compare our results. Table 7 shows the curd moisture values obtained at vat emptying and their standard deviation from the curd moisture values fixed before 
Table 6. Testing suitable algorithm for curd moisture content $( \pm \mathrm{SD})$ prediction $^{1}$

\begin{tabular}{|c|c|c|c|c|c|}
\hline Production & $R_{\text {heating end }}$ & $\mathrm{R}$ & $\begin{array}{l}\text { Curd } \\
\text { moisture }\end{array}$ & $\begin{array}{c}\text { Predicted moisture } \\
\text { content }\end{array}$ & $\mathrm{SEP}^{2}$ \\
\hline A & 0.48 & 0.42 & $56.79 \pm 0.22$ & 56.04 & 0.75 \\
\hline B & 0.51 & 0.37 & $60.39 \pm 1.48$ & 56.51 & 3.87 \\
\hline $\mathrm{C}$ & 0.52 & 0.46 & $56.63 \pm 2.06$ & 60.66 & 4.03 \\
\hline $\mathrm{D}$ & 0.52 & 0.52 & $70.34 \pm 2.06$ & 63.13 & 7.21 \\
\hline $\mathrm{E}$ & 0.52 & 0.51 & $67.32 \pm 0.73$ & 62.96 & 4.36 \\
\hline $\mathrm{F}$ & 0.52 & 0.51 & $68.04 \pm 0.18$ & 62.65 & 5.39 \\
\hline G & 0.52 & 0.34 & $66.34 \pm 0.29$ & 56.61 & 9.73 \\
\hline $\mathrm{H}$ & 0.52 & 0.41 & $68.53 \pm 0.44$ & 59.12 & 9.41 \\
\hline I & 0.52 & 0.40 & $64.52 \pm 0.80$ & 58.76 & 5.76 \\
\hline $\mathrm{J}$ & 0.52 & 0.40 & $49.83 \pm 1.64$ & 53.21 & 3.38 \\
\hline
\end{tabular}

cheese manufacture. As can be observed, the mean curd moisture content obtained in the 4 manufacturing processes at $54 \%$ moisture differed by 4.75 points, whereas for the $57 \%$ moisture cheese, the difference was only 0.43 points. Higher fixed values for moisture content at vat emptying present better sensor prediction results.
This study confirmed the sensor's suitability for controlling curd moisture under industrial conditions. We conclude that this prototype sensor will enable cheese makers to set the desired curd moisture content before cheesemaking, guaranteeing that the selected moisture content is attained in curd before ripening, with lower
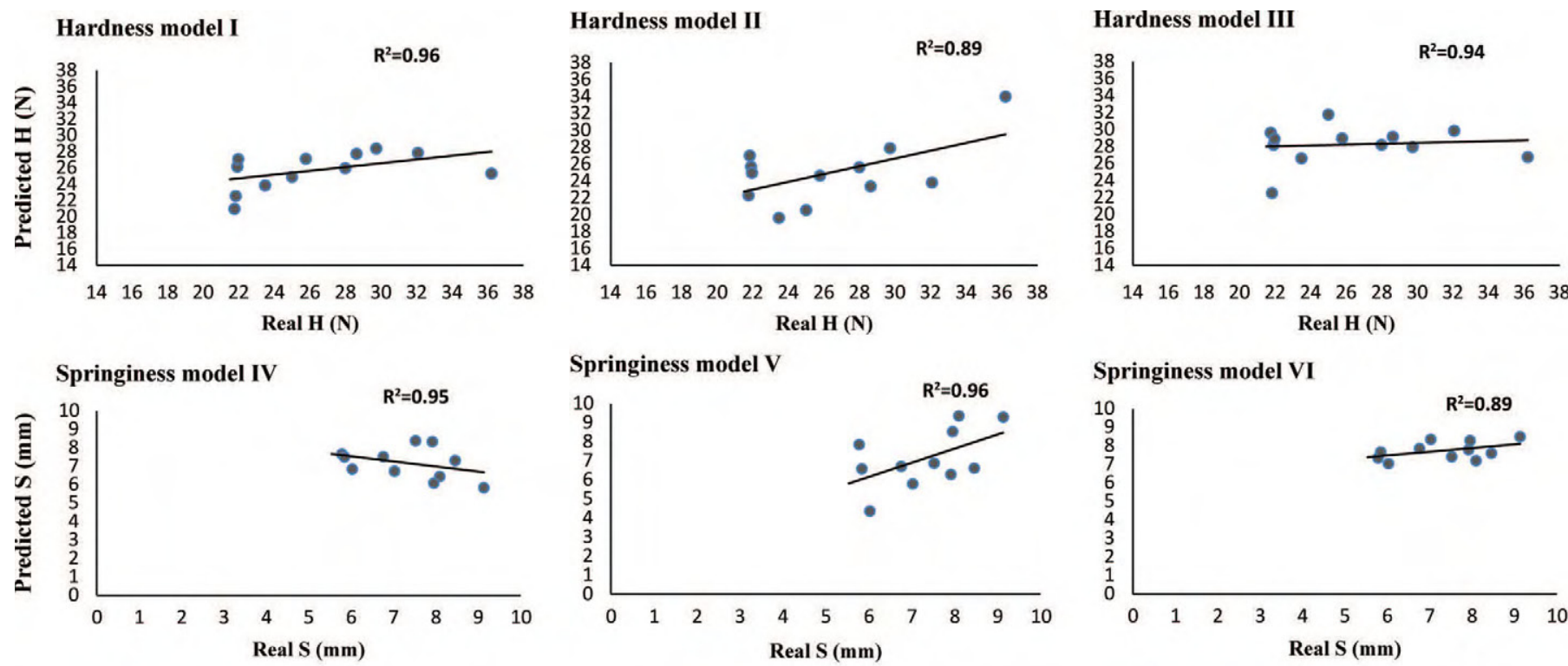

Adhesiveness model VII
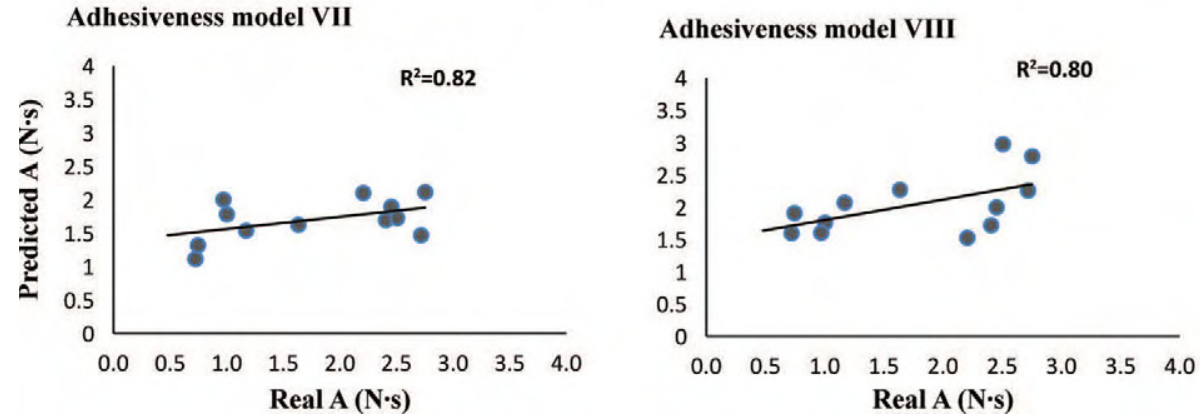

Adhesiveness model IX

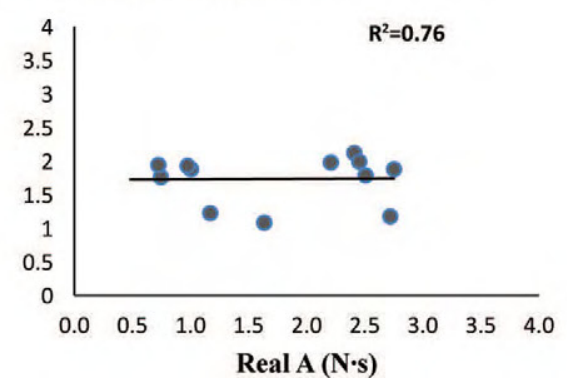

Figure 4. Measured versus predicted cheese texture parameters: hardness (H), springiness (S), and adhesiveness (A); representation of the linear trend from the texture parameter models detailed in Table 5. Color version available in the online PDF. 
Table 7. Controlling moisture by means of a selected prediction algorithm

\begin{tabular}{lccc}
\hline $\begin{array}{l}\text { Selected } \\
\text { moisture } \\
\text { content }\end{array}$ & $\begin{array}{c}\text { Productions } \\
\text { (n) }\end{array}$ & $\begin{array}{c}\text { Curd } \\
\text { moisture } \\
\text { content }^{2}\end{array}$ & SEP $^{3}$ \\
\hline $54 \%$ & 4 & $52.61 \pm 2.31$ & 4.75 \\
$57 \%$ & 4 & $57.50 \pm 0.32$ & 0.43 \\
\hline
\end{tabular}

${ }^{1}$ Number of productions carried out.

${ }^{2}$ Mean value $( \pm \mathrm{SD})$ of the determined moisture content $(\mathrm{M}=85.22$ $\left.\mathrm{R}_{\text {heating end }}+35.66 \mathrm{R}\right)$, where $\mathrm{M}=$ moisture content, $\mathrm{R}_{\text {heating end }}=$ ratio at the end of heating, and $\mathrm{R}=$ sensor ratio.

${ }^{3}$ Mean value of the standard error of prediction (\% of moisture content).

errors than the current error range $(7-15 \%)$ of the same cheese variety under industrial manufacture.

\section{CONCLUSIONS}

The LFV sensor is potentially suitable for the continuous monitoring of both coagulation and syneresis under industrial conditions during goat cheese making. The prediction models developed for moisture content, cheese yield, and textural properties showed promise for applications in cheese making. The prototype LFV sensor enables cheese makers to set a given curd moisture content before cheese manufacture, guaranteeing that the selected moisture level in curd is reached before ripening. These models need to be validated directly by coupling the sensor to industrial vats.

\section{ACKNOWLEDGMENTS}

This work was financially supported by Fundación Séneca project 05721/PI/07. Research grants awarded under the University Staff Training and Research programme of the Spanish Ministry of Education (Spanish Government, Madrid, Spain) and Central Quesera Montesinos S.L. (Murcia, Spain) are also acknowledged.

\section{REFERENCES}

Bourne, M. C. 1978. Texture profile analysis. Food Technol. 41:163178.

Castillo, M., J. A. Lucey, and F. A. Payne. 2006a. The effect of temperature and inoculum concentration on rheological and light scatter properties of milk coagulated by a combination of bacterial fermentation and chymosin. Cottage cheese-type gels. Int. Dairy J. 16:131-146.

Castillo, M., F. A. Payne, C. L. Hicks, J. Laencina, and M. B. López. 2002. Effect of calcium and enzyme in cutting time prediction of coagulating goat's milk using a light scattering sensor. Int. Dairy J. 12:1019-1023.

Castillo, M., F. A. Payne, C. L. Hicks, J. Laencina, and M. B. López. 2003. Effect of protein and temperature on cutting time prediction in goat's milk using an optical reflectance sensor. J. Dairy Res. 70:205-215.
Castillo, M., F. A. Payne, C. L. Hicks, and M. B. López. 2000. Predicting cutting and clotting time coagulating goat's milk using diffuse reflectance, effect of $\mathrm{pH}$, temperature and enzyme concentration. Int. Dairy J. 10:551-562.

Castillo, M., F. A. Payne, T. Wang, and J. A. Lucey. 2006b. Effect of temperature and inoculum concentration on prediction of both gelation time and cutting time. Cottage cheese gels. Int. Dairy J. $16: 147-152$.

Crofcheck, C. L., F. A. Payne, and S. E. Nokes. 1999. Predicting the cutting time of cottage cheese using light backscatter measurements. Trans. ASAE 42:1039-1045.

Dejmek, P., and P. Walstra. 2004. The syneresis of rennet-coagulated curd. Pages 71-103 in Cheese Chemistry, Physics and Microbiology. 3rd ed. Vol. 1. General Aspects. P. F. Fox, P. L. H. McSweeney, T. M. Cogan, and T. P. Guinee, ed. Elsevier Academic Press, Amsterdam, the Netherlands.

Emmons, D. B., C. A. Ernstrom, C. Lacroix, and P. Verret. 1990. Predictive formulas for yield of cheese from composition of milk: A review. J. Dairy Sci. 73:1365-1394.

Fagan, C. C., M. Castillo, C. P. O'Donnell, D. J. O'Callaghan, and F. A. Payne. 2008. On-line prediction of cheese making indices using backscatter of near infrared light. Int. Dairy J. 18:120-128.

Fagan, C. C., M. Castillo, F. A. Payne, C. P. O'Donnell, M. Leedy, and D. J. O'Callaghan. 2007a. Novel online sensor technology for continous monitoring of milk coagulation and whey separation in cheesemaking. J. Agric. Food Chem. 55:8836-8844.

Fagan, C. C., M. Castillo, F. A. Payne, C. P. O'Donnell, and D. J. O'Callaghan. 2007b. Effect of cutting time, temperature and calcium on curd moisture, whey fat losses and curd yield by response surface methodology. J. Dairy Sci. 90:4499-4512.

Fagan, C. C., C. Everard, C. P. O'Donnell, G. Downey, E. M. Sheehan, and C. M. Delahunty. 2007c. Evaluating mid-infrared spectroscopy as a new technique for predicting sensory texture attributes of processed cheese. J. Dairy Sci. 90:1122-1132.

Fagan, C. C., M. Leedy, M. Castillo, F. A. Payne, C. P. O'Donnell, and D. J. O'Callaghan. 2007d. Development of a light scatter sensor technology for on-line monitoring of milk coagulation and whey separation. J. Food Eng. 83:61-67.

Formaggioni, P., A. Summer, P. Franceschi, M. Malacarne, and P. Mariani. 2008. Cheese yield, factors of variation and predictive formulas. A review focused particularly on grana type cheeses. Ann. Fac. Med. Vet. Parma 28:211-232.

Guo, M., Y. W. Park, P. H. Dixon, J. A. Gilmore, and P. S. Kindstedt. 2004. Relationship between the yield cheese (Chevre) and chemical composition of goat milk. Small Rumin. Res. 52:103-107.

ISO. 1997. Cheese: Determination of moisture content. ISO standard 1442. International Organization for Standardization, Geneva, Switzerland.

Mateo, M. J., D. J. O'Callaghan, C. D. Everard, M. Castillo, F. A. Payne, and C. P. O'Donell. 2010. Evaluation of on-line optical sensing techniques for monitoring curd moisture content and solids in whey during syneresis. Food Res. Int. 43:177-182.

Mateo, M. J., D. J. O'Callaghan, C. D. Everard, C. C. Fagan, M. Castillo, F. A. Payne, and C. P. O'Donell. 2009. Influence of curd cutting programme and stirring speed on the prediction of syneresis indices in cheese-making using NIR light backscatter. Lebenson. Wiss. Technol. 42:950-955.

Payne, F. A., R. C. Freels, S. E. Nokes, and R. S. Gates. 1998. Diffuse reflectance changes during the culture of cottage cheese. Trans. ASAE 41:709-713.

Payne, F. A., R. S. Gates, and B. L. Fannin. 1997. Measurement precision for a fiber optic diffuse reflectance sensor. Trans. ASAE 39:2163-2198.

Payne, F. A., C. L. Hicks, S. Madangopal, and S. A. Shearer. 1993. Fibre optic sensor for predicting the cutting time of coagulating milk for cheese production. Trans. ASAE 36:841-847.

Rovira, S., V. Garcia, and M. B. López. 2011. Application of a large field of view sensor during manufacture of fresh goat cheese. Int. J. Dairy Technol. 64:1-6. 